\title{
The non-maximality-solution to counterfactual scepticism
}

\author{
Daniel Dohrn ${ }^{1}$
}

Received: 14 November 2019 / Accepted: 23 July 2020 / Published online: 5 August 2020

(c) The Author(s) 2020

\begin{abstract}
The following semantics for counterfactuals is fairly standard: for a counterfactual to be true, the closest antecedent worlds have to be consequent worlds. Closeness is measured by overall similarity of worlds to an evaluation world. There is a range of interrelated challenges to this account: counterfactual scepticism, 'Hegel'-, 'Sobel'-, and 'Heim'-sequences. So far there is no unified solution to these challenges. I discuss a solution that preserves the standard semantics by writing the shifty parameter into pragmatics. The solution has been suggested by Križ for Sobel- and Heim-sequences, yet I argue that it can be generalized to counterfactual scepticism. Conditionals are subject to a pattern which is familiar from descriptions. Everyday counterfactuals are semantically homogeneous and pragmatically non-maximal. Homogeneity: a counterfactual is neither true nor false if only some but not all closest antecedent worlds are consequent worlds. Non-maximality: in many contexts, not all but only practically all closest antecedent worlds have to be consequent worlds for the utterance of a counterfactual to say something true if the difference does not matter for the purposes of conversation.
\end{abstract}

Keywords Conditional - Counterfactual - Scepticism - Sobel sequence - If · Subjunctive $\cdot$ Counterfactual scepticism · Modal · Homogeneity · Imprecision · Semantics $\cdot$ Pragmatics

\section{Introduction}

The following semantics for counterfactuals is fairly standard: a counterfactual is true precisely if all closest antecedent worlds are consequent worlds. Closeness is spelled

$\triangle$ Daniel Dohrn

Daniel.Dohrn@unimi.it

1 Dipartimento di Filosofia, Università degli Studi di Milano, Via Festa del Perdono 7, 20122 Milan, Italy 
out by an ordering of worlds according to their similarity to an evaluation world, normally the actual one. This picture has been so successful that we should not give it up easily. I shall consider a range of problems for the standard semantics and argue that they can be accommodated by a minimal amendment to the semantics plus pragmatics. The minimal amendment preserves the letter of the standard semantics as stated. ${ }^{1}$

I give an outline of the argument to come. (2.) I list the problems: counterfactual scepticism, 'Hegel'-, 'Sobel'-, and 'Heim'-sequences. (3.) I introduce semantic homogeneity and pragmatic non-maximality for (3.1.) descriptions and (3.2.) counterfactuals. (4.) I summarize how (4.1.) non-maximality explains unidirectionality in Sobel- and Heim-sequences and (4.2.) how lessons from counterfactual scepticism contribute to that explanation. (5.) I discuss transferring the solution to counterfactual scepticism. (5.1.) I give an overview of the solution. (5.2.) I elaborate on the versatility of the solution. (5.3.) I consider retraction evidence.

\section{Interrelated challenges: counterfactual scepticism, Sobel- and Heim-Sequences}

I outline a range of interrelated challenges, starting with counterfactual scepticism (Hájek ms). Everyday counterfactuals are threatened with falsity. Consider a delicate china plate. Normally, we would accept

(1) If the plate had been dropped, it would have shattered.

Applying lessons from quantum physics, while the plate shatters in the overwhelming majority of closest worlds where it is dropped, there are some closest worlds where, due to an amazing coincidence in the lawful trajectories of the individual molecules forming the plate, it flies off instead of shattering.

The argument does not depend on metaphysical indeterminism. Even if the actual world is deterministic, there are many ways for macroscopic antecedents as in (1) to be microphysically realized, and we are largely ignorant about the particular microphysical details of the actual world. We cannot exclude that some way for the plate to be dropped is both closest to the microphysical make-up of the actual world and supports the plate's flying off sideways.

In light of these arguments, we should accept:

(2) If the plate had been dropped, it might have flown off sideways and then it would not have shattered.

Assuming 'would' and 'might' are duals ('might $P$ ' precisely if 'not would not $P$ '), (1) and (2) are inconsistent. Denying duality does not dissolve the underlying concern (cf. Lewis 1986, p. 64): some world where the plate flies off sideways is as similar to actuality as the most similar worlds where it shatters. As a consequence, everyday counterfactuals like (1) are threatened with falsity. One may react by demoting worlds where the plate flies off sideways from being closest due to their remarkability (Williams 2008). Yet all such moves are jeopardized by a further facet of the problem. (1) and (2) cannot be freely combined. The sequence (1)-(2) seems all right:

\footnotetext{
1 The solution concerns the everyday use of counterfactuals. The amendment to the standard account may not apply to the more regimented use of counterfactuals in scientific reasoning.
} 
(1) If the plate had been dropped, it would have shattered;

(2) (if the plate had been dropped), it might have flown off sideways and then it would not have shattered.

The reverse sequence feels infelicitous:

(2) If the plate had been dropped, it might have flown off sideways and then it would not have shattered;

(1) \#(if the plate had been dropped,) it would have shattered.

A solution to counterfactual scepticism should explain why (1) and (2) interact in this way; the moves considered so far do not explain it.

A related phenomenon are 'Hegel'-sequences and their reversal (Gillies 2007, pp. 342-343):

(3) If Sophie had gone to the parade, she would have seen Pedro dance;

(4) if Sophie had gone to the parade, she might have been stuck behind someone tall and then wouldn't have seen Pedro dance.

The forward-directed sequence seems all right, the reversal seems infelicitous:

(4) If Sophie had gone to the parade, she might have been stuck behind someone tall and then wouldn't have seen Pedro dance;

(3) \#if Sophie had gone to the parade, she would have seen Pedro dance.

Another related phenomenon are 'Sobel'-sequences (Lewis 1973, p. 10). We can build an example which is analogous to (3)-(4):

(3) If Sophie had gone to the parade, she would have seen Pedro dance;

(5) if Sophie had gone to the parade and been stuck behind someone tall, then she wouldn't have seen Pedro dance.

This sequence seems all right. However, just as in the case of a Hegel-sequence, the reversal of such a sequence normally sounds infelicitous (cf. von Fintel 2001). The infelicitous reversal is sometimes called a 'Heim'-sequence:

(5) If Sophie had gone to the parade and been stuck behind someone tall, she wouldn't have seen Pedro dance;

(3) \#if Sophie had gone to the parade, she would have seen Pedro dance.

Lewis's (1973) version of the standard account has been designed to explain how the normal sequence (3)-(5) can be true, but does not yet provide an explanation of the infelicity of the reverse sequence. The forward-directed sequence is true under the following conditions: the closest worlds where Sophie goes to the parade are closer than the closest worlds where she goes to the parade and gets stuck. In the former, she sees Pedro, in the latter, she does not. So far there is no reason why such a truthapt sequence should not be felicitously uttered. The same should go for the reverse sequence.

I shall give a schematic presentation of all sequences (1)-(2), (3)-(4), (3)-(5) and their reversal. 
Hegel-sequence:

(n) If $A, C$.

$(\mathrm{n}+1)$ If $A$, might $B$ and then not $C$.

$(\mathrm{n}+1)$ If $A$, might $B$ and then not $C$.

(n) If $A, C$.

Sobel-sequence:

(n) If $A, C$.

$(\mathrm{n}+1)$ If $A \& B, \operatorname{not} C$.

$(\mathrm{n}+1)$ If $A \& B$, not $C$.

(n) If $A, C$.

I shall call the counterfactuals where $B$ figures either in the antecedent or in the 'might'-consequent $A \& B$-counterfactuals, the others just $A$-counterfactuals.

The extant unified approaches to these problems more or less strongly revise the standard semantics. ${ }^{2}$ I shall defend a different general approach. It addresses all the problems and does so with a minimal amendment that is compatible with the letter of the standard semantics as initially characterized. The solution has been developed for Sobel- and Heim-sequences by Križ $(2015,2016)$, but it so far has not been applied to counterfactual scepticism. Such an application is tempting given the parallels between counterfactual scepticism and the problem of Sobel-sequences and their reversal.

The approach combines semantics and pragmatics. One may question the distinction of semantics and pragmatics, but once it is accepted, there are strong motivations to apply it to the challenges considered. Any solution is likely to come with a lot of casuistry. It is perfectly in the spirit of the standard account in the tradition of Stalnaker to confine such casuistry to pragmatics while keeping the semantics as general and systematic as possible (cf. Stalnaker 1968, section V; Moss 2012). Gauker nicely summarizes received wisdom:

Roughly, what belongs to the semantics is everything on which the truth value of a sentence depends... Thus, everything belongs to semantics in terms of which we give a recursive definition of truth in a model... What belongs to pragmatics is our explanations of the ways in which speakers can exploit the truth conditions of sentences, or the capacity of sentences to express propositions in context, to mean things by what they say. (Gauker 2005, p. 41)

Semantics deals with general rules of building up the truth-conditions of sentences from the meaning of their components. In contrast, pragmatics deals with the things we do with these sentences. It requires to dirty one's hands with casuistry, to go into the details of the specific contexts of utterances. Other things being equal, it is preferable to write context-relativity and shiftiness into pragmatics and keep the semantics general and simple. A pragmatic solution is attractive if one wants to preserve orthodoxy about counterfactuals.

\footnotetext{
2 Pragmatic accounts of Sobel- and Heim-sequences have been presented by Moss (2012), Klecha (2015, 2018), Ippolito (2020). Moss (2013) also addresses counterfactual scepticism, but she radically departs from standard semantics in replacing truth-conditions by constraints on rational credences. Paradigmatic semantic approaches to (some of) the problems considered are von Fintel (2001), Gillies (2007), Asher and McCready (2007) and Lewis (2016, 2018).
} 
The solution combines a semantic and a pragmatic claim. The semantic claim is that counterfactuals are homogeneous: there is a third alternative between truth and falsity. The pragmatic claim is that utterances of counterfactuals often have to be read non-maximally: although they are neither true nor false, semantically speaking, they can be felicitously uttered to state that (not all but) practically all closest antecedent worlds are consequent worlds. Homogeneity and non-maximality can be more easily observed in descriptions. For this reason, I shall first consider descriptions and then proceed to counterfactuals.

\section{Semantic homogeneity and pragmatic non-maximality}

\subsection{Descriptions}

\subsubsection{Homogeneity in descriptions}

Homogeneity is most obvious in descriptions. Before summarizing some examples from the literature, I add a note of caution. While some minimum context is specified, the examples rely on our tendencies to supplement the context by certain expectations about the normal context. They are convincing only as long as normal speakers share these expectations. The point also applies to the exemplary counterfactuals, but it is especially important for incomplete descriptions because they strongly depend on contextual salience.

Given our expectancies about a normal context, the following utterances seem infelicitous:

\section{DIALOGUE 1}

Context: talking about books in a library (half of the books are in Dutch):

Al: (6) \#The books are in Dutch.

Bo: (7) \#It is not the case that the books are in Dutch.

Alternatively Bo: (8) It is not the case that all the books are in Dutch.

Al's utterance of (6) seems infelicitous. The same goes for its outer negation (7), as contrasted to the negation of an explicit universal quantification (8). This can be explained as follows: the utterance of (6) does not seem true. As for (7), an outer negation it is not the case that the $F$ are $G$ is different from the inner negation the $F$ are not $G$, which is used to deny that the predicate $G$ applies to a range of maximally salient $F$. The outer negation says that the negated sentence is false (Chierchia and McConnell-Ginet 1999, p. 76). All the books are in Dutch satisfies the requirement for the outer negation to be true. It is clearly false. The infelicity of (7) indicates that (6) is different. While (6) does not seem true, we also hesitate to disqualify it as false.

Semantic Homogeneity explains our intuitions about (6)-(7). There are two different interpretations of homogeneity. According to Von Fintel (1997, Sect. 7.2.2), (6) comes with a homogeneity presupposition that either all maximally salient books are in Dutch or none of them are. The infelicity of (6) and (7) is due to a presupposition failure.

An alternative approach is to directly write homogeneity into the truth-conditions of (6): the $F$ are $G$ is true precisely if all contextually maximally salient $F$ are $G$ and 
false precisely if no maximally salient $F$ is $G$. Otherwise it is neither true nor false (Križ and Chemla 2015; Križ 2015, 2016). The advantage of this alternative is that it comes with a concrete proposal for explaining two opposite observations: on the one hand, there is the infelicity of (6) and (7) as noted above. On the other hand, we shall see that descriptions can often be felicitously uttered although the homogeneity condition is not satisfied. Perhaps these varieties in felicity can be reconciled with the diagnosis of a presupposition failure, but it is not obvious how such a reconciliation is to be achieved. I shall therefore adopt the second alternative of directly writing homogeneity into the truth-conditions of descriptions.

\subsubsection{Non-maximality in descriptions}

I have announced that there are felicitous uses of descriptions although the homogeneity condition is not satisfied. They arise as follows: an incomplete description the $F$ are $G$ is usually taken to select precisely the contextually most salient $F$. However, often there are tolerable exceptions among the contextually maximally salient $F$. I present an example from Križ (2016, p. 498), again emphasizing that it depends on certain background expectations on how to supplement the minimal context given:

Context: all the professors except Smith smiled and then left, leaving Smith behind.

(9) The professors smiled.

(10) \#The professors smiled and then all left the room.

One may try to explain the felicity of (9) by domain restriction: some domain of quantification is restricted to the smiling professors. But then the utterance of (10) should also be felicitous. ...then all left the room would quantify over the restricted domain. To account for the difference between (9) and (10), the professors in (9) must not be read as all the professors in a contextually restricted domain, excluding Smith, but as allowing for exceptions from a set of contextually most salient professors, which includes Smith.

Here is a first take on non-maximality: on the one hand, there is a maximal reading. The maximal reading selects all and only the contextually most salient individuals. It can be made explicit by a corresponding universal quantification over a contextually restricted domain (all professors smiled). On the other hand, examples like (9) provide evidence that many contexts do not only privilege a certain set of most salient individuals which satisfy some description. These contexts also fix some range of tolerable departures from this set. Within that range, it does not matter whether the predicate is true of all individuals in the set, or whether there are exceptions. (9) is acceptable if it only matters that almost all maximally salient professors smiled, i.e. Smith not smiling is a tolerable exception. Context determines not only the set of maximally salient professors, but also how many of the professors in the set have to smile for (9) to be acceptable.

How is the difference in felicity between (6) and (7) on the one hand and (9) on the other hand to be explained? In the most natural reading of Al's utterance of (6) (the books are in Dutch), (6) is infelicitous not simply because not all maximally salient books are in Dutch; the books which are not in Dutch do not seem a tolerable departure from the set of maximally salient books either. I have pointed out that our verdict on 
these examples is guided by certain background expectations about the context. The expectations supplement the explicit stipulations: we might be able to conjure up a context in which (6) is in order, but it would need elaboration. For instance, (6) may be in order in the following special situation: the question is whether the policy of the library is rather to buy books in Dutch or in German, and as a matter of fact there are no German books in the library. Our take on (9) also depends on background assumptions, but we readily supplement the sparse context by the background that is required for Smith to be a tolerable exception.

Whereas homogeneity is usually construed as a semantic phenomenon, Križ construes non-maximality as a pragmatic phenomenon. It arises from a process of coordinating semantic meaning with the current purpose of conversation. Such a purpose does not reduce to the explicit questions raised in a conversation:

What speakers of English mean when they use the phrase current purposes is rarely just the immediate last question that has been asked in the conversation. Rather, it would seem that they refer to something like the overarching goals of the participants, as relevant to this conversation. This is what we take the current issue to represent. (Križ 2015, p. 86)

The elusiveness of current purposes limits the predictive power of the theory, but it gives us a lot of flexibility to handle the challenges considered.

Assume the contextual issue addressed by (9) is whether practically all professors smiled. There are two relevant possibilities: either sufficiently many (of the most salient) professors smiled, including the possibility that all of them did, or it is not the case that sufficiently many professors smiled. When we encounter an utterance of ( 9 ) in this situation, we reason as follows: if a speaker were to use (9) in order to convey that the semantic truth-condition is satisfied (all professors smiled), she would not perfectly address the issue. She would convey too much information, violating the Gricean maxim of quantity. What the speaker must convey in order to perfectly address the issue is just that the situation is equivalent to one in which the semantic truth-condition of (9) is satisfied for the purposes of conversation. We interpret her utterance accordingly.

To be sure, there are semantically true alternative expressions in the neighbourhood: all professors except Smith smiled. Yet (9) serves as well as these alternatives to provide the contextually relevant information. The choice between the informationally equivalent alternatives reduces to considerations as captured by Grice's maxim of manner. (9) is chosen if it fares best with regard to manner. It is shorter, requires less cognitive effort etc. (cf. Krifka 2002). All that is conveyed is that the situation is equivalent to a situation where (9) is true for the purposes of conversation: practically all professors smiled.

There are different ways of elaborating this pragmatic explanation. The most advanced proposal (Križ 2016) among several competitors (e.g. Malamud 2012) bases non-maximality as a pragmatic phenomenon on homogeneity as a semantic phenomenon. One of its advantages is a succinct division of labour between semantics and pragmatics.

Here is the analysis as it stands: in order to be assertible in a context, a sentence $S$ must address a contextual issue. The issue comes with a contextual partition of alternatives that is of current interest. The alternatives concern what the actual world 
is like. ${ }^{3}$ A necessary condition for $S$ to address the issue is that no cell in the partition at issue contains both an alternative where $S$ is semantically true (s-true) and an alternative where $S$ is semantically false (s-false). In contrast, there may well be a cell in the partition which contains alternatives where $S$ is s-true and alternatives where $S$ is neither s-true nor s-false. For an utterance of $S$ to convey something true, there must be a unique cell $C$ in the partition which contains alternatives where $S$ is s-true, and the actual world must fall into $C$. $C$ may also contain alternatives where $S$ is not s-true. $S$ is chosen among all expressions which satisfy the same condition for conveying something true if it fares better with regard to manner. In this situation, the utterance of $S$ conveys that the true alternatives fall into $C$.

To account for the pragmatic reasoning, Križ (2016, pp. 501-502) weakens the maxim of quality: the maxim is not that $S$ must be s-true to be assertable but that the actual world must belong to the same cell as an alternative where $S$ is s-true. All alternatives in this cell are 'as good as true', equivalent to an alternative where $S$ is s-true for the purposes of conversation.

I shall illustrate the proposal by the example of the smiling professors: assume

(9) The professors smiled

is truly uttered although Smith did not smile. Then the issue must come with a partition of the following sort: there is a unique cell $C_{P}$ in the partition which contains an alternative where all (maximally salient) professors smiled and an alternative where only Smith did not smile. Worlds where too many professors did not smile are not part of $C_{P}$. By uttering (9), one conveys that the actual world falls into $C_{P}$, which contains only the tolerable exceptions. (9) is used to say something true precisely if all professors but for some tolerable exceptions smiled.

I add two important qualifications: firstly, an outer negation as in (7) (it is not the case that the books are in Dutch) does not tolerate homogeneity and non-maximality in the sentence negated. It requires that the negated sentence has a determinate semantic truth-value.

Secondly, once an exception has been mentioned, it cannot be neglected. In the example of the smiling professors, asserting (9) is inappropriate once it has been mentioned that Smith did not smile:

DIALOGUE 2

All the professors except Smith smiled and then left, leaving Smith behind.

$\mathrm{Al}$ : Smith didn't smile.

Bo: (9) \#The professors smiled.

How are we to explain this? Al's utterance must address a contextual issue where it matters whether Smith smiled. Hence it either responds to an issue which does not allow us to neglect Smith, or it creates such an issue to be addressed by the utterances to come.

Why does Bo's utterance not in turn shift the issue such as to neglect the exceptions? Highlighting exceptions that have been neglected can be interpreted as raising

\footnotetext{
3 Križ describes the alternatives as possible worlds. I take them to be epistemic rather than metaphysical. Križ insists that the partition may contain possible worlds which we are in a position to rule out. I thus have to assume that epistemic alternatives may form part of the contextually relevant partition although we are in a position to rule them out.
} 
the standards of precision. As Lewis noted, there is an asymmetry between raising and lowering the standards. The former is always 'commendable', the latter is not (cf. 1979, 352-353). To explain this observation, I suggest to follow Lauer (2012): even when non-maximality is permissible, a speaker incurs a commitment to the semantic truthcondition (s-truth) of her utterance. She can expect to 'get away' with a non-maximal utterance as long as it optimally addresses the conversational issue. Still any interlocutor may insist on satisfying the semantic truth-condition. Any interlocutor may change the conversational issue by raising an exception to salience, thereby signaling that she will not let the other speakers get away with neglecting the exception. ${ }^{4}$

\subsection{Counterfactuals}

\subsubsection{Homogeneity in counterfactuals}

In recent literature, close parallels have been drawn between descriptions of the form the $F$ are $G$ and talk about possibilities (Bittner 2001). It has even been suggested that conditionals and descriptions alike can be interpreted by structurally analogous choice functions (Schlenker 2004). In light of close connections between descriptions and conditionals, it should not come as a surprise that counterfactuals also display homogeneity, as suggested by von Fintel (1997) and Križ $(2015,2016)$.

The following dialogue provides evidence that counterfactuals display homogeneity:

\section{DIALOGUE 3}

$\mathrm{Al}$ : (1) If the plate had been dropped, it would have shattered.

Bo: (11) But would it definitely have shattered?

Al: No. I admit that,

(2) if the plate had been dropped, it might have flown off sideways and then it would not have shattered.

Hence (what I said was not quite right):

(12) it is not the case that, if the plate had been dropped, it WOULD/would definitely have shattered. ${ }^{5}$

(12) is contrasted to

(13) \#It is not the case that, if the plate had been dropped, it would have shattered.

\footnotetext{
4 Klecha (2018) explains the asymmetry as an asymmetry of signaling. Statements which are costly in terms of manner can only be used if high-precision standards are assumed. Thus, they can be used to manifest high standards. In contrast, one cannot use statements which fare well with regard to manner in order to manifest low standards. For they may as well be used in high-precision contexts to claim that their semantic truth-conditions are satisfied. I doubt that this explains why raising the standards is commendable in the first place.

5 Križ (2015, p. 41) notices the analogy between definitely and all in the case of vague predicates. As a way of enforcing the condition that all closest antecedent worlds be consequent worlds, he rather uses necessarily (2015, p. 175). I think both expressions can be used in the latter way, and both are ambiguous between different uses. One advantage of using definitely in the case of counterfactuals is that it avoids the following ambiguity: necessarily may also be read as a necessity modal, as when one says 'If Goldbach's Conjecture were true, it would be necessarily true'.
} 
Embedded in the negation (13) in Dialogue 3, the negated sentence (1) does not seem true any longer, but it does not seem false either. The intuitive difference in felicity between (12) and (13) parallels the difference between (7) (it is not the case that the books are in Dutch) and (8) (it is no the case that all the books are in Dutch). Following Križ (2015), our intuitions can be explained in the same way. We do not accept an outer negation as true unless the negated sentence is false. (13) and (7) are cases where the negated sentences are neither true nor false, hence we are reluctant to accept the outer negation. In contrast, (12) and (8) are acceptable because the negated sentences are false.

Now there is a striking difference between (6) (the books are in Dutch) and (1). The utterance of (1) seems perfectly acceptable, and it had better say something true on pain of counterfactual scepticism. In this respect, (1) rather resembles (9) (the professors smiled). Indeed someone might respond to (9) by

(14) No. It is not the case that all the professors smiled.

Yet one cannot respond

(15) No. The professors didn't smile.

This parallel is evidence that the infelicity of the outer negation (13) as contrasted to (12) can be explained by homogeneity, even if the utterance of (1) says something true. To be sure, we still lack an explanation of how (1) can be used to say something true.

The parallel drawn between descriptions and conditionals supports the following semantic homogeneity hypothesis for everyday counterfactuals: a counterfactual is true precisely if all closest antecedent worlds are consequent worlds, false precisely if none of them are, otherwise indeterminate. Homogeneity is ruled out by 'WOULD' counterfactuals, which in this respect resemble the explicit universal quantification in (8). They are false unless all closest antecedent worlds are consequent worlds. The distinction between 'would' and 'WOULD' explains the difference in felicity between (12) and (13).

It remains to be explained why $\mathrm{Al}$ may nevertheless truly utter (1) at the beginning of DIALOGUE 3 although (1) is not semantically true and he even retracts it later. The explanation will allow me to respond to counterfactual scepticism.

\subsubsection{Non-maximality in counterfactuals}

I shall now elaborate the proposal that counterfactuals also display non-maximality. As we have seen, homogeneity is the semantic phenomenon that there is a third option between truth and falsity: applied to counterfactuals, they are often neither true nor false. Non-maximality, applied to counterfactuals, is the phenomenon that, for a counterfactual to convey something true in a context, not all but only practically all closest antecedent worlds have to be consequent worlds.

Besides semantic truth-conditions, there is a further -pragmatic- factor. When using a counterfactual like (1), we address a conversational issue. When we settle for a nonmaximal reading, the semantic truth-condition of the counterfactual is not satisfied, i.e. not all closest antecedent worlds are consequent worlds. Yet we do not distinguish 
among several alternatives: we only want to know whether practically all closest antecedent worlds are consequent worlds and do not distinguish whether all closest antecedent worlds or all such worlds save some exceptions are consequent worlds.

In this situation, a speaker is faced with the choice among several alternative expressions, which meet the following condition: if their semantic truth-condition is satisfied, sufficiently many closest antecedent worlds are consequent worlds. Since these alternative expressions are informationally equivalent with regard to the issue addressed, we choose the one that excels with regard to manner. The counterfactual is chosen as it fares best in this regard.

The non-homogeneous 'WOULD'-conditional remains as an expressive resource of enforcing semantic truth as the only determinant of the final meaning. Since the 'WOULD'-counterfactual can be used only if the semantic truth-condition is satisfied, it can only be interpreted as saying that all closest antecedent worlds are consequent worlds.

There is further evidence for non-maximal readings of counterfactuals. In everyday life, we use counterfactuals far more generously than one would expect from the standard account sans pragmatic amendment. One may dismiss these ways of using counterfactuals as irregular. But non-maximality opens up an attractive option of systematically treating them as a pragmatic phenomenon. Consider the following example from the psychological literature:

[16] If we were to eat the chicken then we would get sick.

We might assert the counterfactual [16] about some only partially cooked chicken

that has been left out in the sun at a picnic. (Evans and Over 2004, p. 125)

I have encountered mixed reactions about (16). The non-maximality approach does not come with a commitment to accepting (16) in particular, but the example can be used to illustrate the approach. I shall therefore assume that (16) is acceptable. I guess that the objective probability of getting sick in the situation described is not very high. Yet it seems that we do not need a high probability for (16) to convey something true in the example.

Consider the alternative of treating (16) as semantically true à la Karen Lewis (2016, 2018): the most similar worlds where we eat the chicken and do not get sick are less relevant than worlds where we get sick and thus do not count towards the truth of (16). ${ }^{6}$ I find it implausible to treat such worlds as less relevant. Lewis herself maintains that 'high probability (conditional on the antecedent) macroscopically described outcomes are always relevant.'(Lewis 2018, p. 501). The conditional probability of the consequent being false given the antecedent may in some counterfactuals like (16) come close to a high-probability outcome. It won't help either to reinterpret the similarity ordering in terms of normalcy (Williams 2008) as getting sick presumably does not qualify as the normal outcome. ${ }^{7}$

\footnotetext{
6 Lewis (2016) presents two variants: in one variant, closeness is a function of similarity and relevance. In the second, the truth-condition is that only the relevant worlds among the most similar antecedent worlds have to be consequent worlds. The explanation for the truth of (16) in both alternatives is that worlds where we eat the chicken and stay healthy are dismissed as not sufficiently relevant.

7 Križ applies non-maximality to generics like 'mosquitoes carry malaria', which seems true although only a minuscule fraction of mosquitoes carries malaria (2015, p. 186).
} 
Indeed worlds in which we eat the chicken without getting sick do seem relevant. They represent the ideal outcome for us. Our acceptance of (16) seems to be due to weighing the proportion of closest worlds in which we get sick among all closest worlds, including those in which we don't get sick, the threshold for that proportion being low.

In light of these findings, it seems attractive to take a more differentiated stance towards (16) rather than either dismissing it as non-literal or false or accepting it to be (semantically) true. (16) is not true, semantically speaking, but may be used to pragmatically convey something true: we do an implicit risk-benefit analysis of eating the chicken. We set a threshold for the proportion of worlds at which we get sick among all closest antecedent worlds. As long as the threshold is met, it does not matter whether we get sick in all closest antecedent worlds or only in a significant proportion of them. The utterance of (16) conveys that this low threshold is met.

\section{Križ's non-maximality approach to Sobel- and Heim-sequences}

\subsection{Outline of the solution}

Coming to the problems mentioned in the initial section, Križ explains the asymmetry between felicitous Sobel-sequences and infelicitous reversals by non-maximality $(2015,7.1 .7.){ }^{8}$ Take again the schema of a Sobel- and a Heim-sequence:

(n) If $A, C$.

$(\mathrm{n}+1)$ If $A \& B, \operatorname{not} C$.

$(\mathrm{n}+1)$ If $A \& B$, not $C$.

(n) If $A, C$.

When a Sobel-sequence is felicitous but its reversal is not, the $A$-counterfactual is not semantically true as there are $A \& B$-worlds among the closest $A$-worlds. In some of these worlds, the consequent $C$ is false. However, it is taken for granted in the presumed context that the latter $A \& B$-worlds are admissible exceptions among the closest $A$-worlds. It does not matter whether all closest $A$-worlds or all closest $A$-worlds save some $A \& B$-worlds are $C$-worlds. Hence the $A$-counterfactual can be felicitously uttered to say something true: practically all closest $A$-worlds are $C$-worlds. As for the $A \& B$-counterfactual, it also can be truly uttered provided practically all closest $A \& B$ worlds save perhaps for some tolerable exceptions are not $C$-worlds. The standards for 'practically all' may differ for the $A$-counterfactual and the $A \& B$-counterfactual.

Things are different for the reversal. The $A \& B$-counterfactual uttered first makes the $A \& B$-worlds which are not $C$-worlds salient as exceptions among the closest $A$-worlds. The conversational context for subsequently uttering the $A$-counterfactual differs from the one encountered in the forward-directed sequence. Normally, a change

\footnotetext{
8 Klecha $(2015,2018)$ presents a closely related pragmatic account of Sobel-sequences, based on a more general pragmatic theory of imprecision. While it remains to be seen how homogeneity and non-maximality relate to imprecision more generally, the resulting pragmatic approach to Sobel- and Heim-sequences does not differ much from Križ's. The main difference is that even semantically false statements can be used to say something true. For instance, one may say 'she arrived at three' although she arrived at 15.05.
} 
of context affects the subsequent utterances and not the preceding ones. Downstream from the utterance of the $A \& B$-counterfactual, it matters whether all closest $A$-worlds or all closest $A$-worlds save some $A \& B$-worlds are $C$-worlds. In this context, the $A$ counterfactual cannot be uttered to say that practically all $A$-worlds are $C$-worlds. It has to be interpreted as saying that all closest $A$-worlds are $C$-worlds, including the $A \& B$-worlds. ${ }^{9}$ This claim conflicts with the claim made by the $A \& B$-counterfactual. The sequence in context becomes inconsistent.

The diagnosis of the reversal forces me to revisit a variant of the felicitous forward-directed sequence. In this variant, the $A \& B$-counterfactual also has to be read non-maximally as there are $C$-worlds among the closest $A \& B$-worlds. If the $A \& B$ counterfactual raises to salience some closest $A$-worlds which are not $C$-worlds, why doesn't the $A$-counterfactual likewise raise to salience the $C$-worlds that form exceptions among the closest $A \& B$-worlds? My suggestion is the following: if we already accept that $A \& B$-worlds figure among the closest $A$-worlds, an utterance of the $A \& B$ counterfactual can be true only if there are not $C$-worlds among the closest $A$-worlds, whether it is read non-maximally or not. Yet an $A$-counterfactual may be true even if all closest $A \& B$-worlds are $C$-worlds, provided it is read non-maximally. Hence the $A \& B$-counterfactual manifests that there are exceptions (not $C$-worlds) among the closest $A$-worlds, whereas the $A$-counterfactual does not manifest that there are exceptions among the closest $A \& B$-worlds.

The proposal can be illustrated by the standard example:

(3) If Sophie had gone to the parade, she would have seen Pedro dance;

(5) if Sophie had gone to the parade and been stuck behind someone tall, then she wouldn't have seen Pedro dance.

When considering the sequence (3)-(5) out of the blue, we can well imagine that it could be truly uttered. It may nevertheless be helpful to conjure up an exemplary context. You inform someone after the parade that Sophie would have liked to see Pedro but could not attend. You want to convey that, in the relevant majority of situations that interests your interlocutor, Sophie also would have seen Pedro. Yet to be clear, you make explicit that you presume the issue to be streamlined by disregarding certain disturbing circumstances, among them Sophie getting stuck behind someone tall.

As far as there are closest parade-going worlds where Sophie gets stuck, (3) is not semantically true. Still your utterance of (3) is true as the issue permits a non-maximal reading. Sophie sees Pedro in practically all closest parade-going worlds, although there are some where Sophie does not see Pedro. In contrast, (5) may be truly uttered provided Sophie does not see Pedro in practically all closest worlds in which she gets stuck.

Coming to the reversal

(5) If Sophie had gone to the parade and been stuck behind someone tall, she wouldn't have seen Pedro dance;

(3) \#if Sophie had gone to the parade, she would have seen Pedro dance.

An utterance of (3) seems infelicitous as the worlds raised to salience by an utterance of (5) cannot be disregarded. The issue for (3) to address inevitably becomes a more

\footnotetext{
9 To be sure, one may still neglect other exceptions.
} 
fine-grained one compared to considering (3) out of the blue: it makes a difference whether all closest parade-going worlds, or whether all of these worlds except (most of) the worlds at which Sophie gets stuck are worlds where she sees Pedro. An utterance of the sequence normally leads to making inconsistent claims: it is claimed that Sophie sees Pedo also at (most of) the closest worlds at which she gets stuck, and that she does not see him at these worlds.

The account can be easily generalized to other cases where an exception is raised to salience:

Do you remember when Kate got stuck behind a tall person and missed seeing Pedro in her first baseball parade?

(3) \#But if Sophie had gone to the parade, she would have seen Pedro dance. (cf. Moss 2012, p. 578; Nichols 2017, 3.4.)

There are indirect ways of raising worlds where Sophie gets stuck and does not see Pedro to salience. Many of these ways bear on the issue addressed. Remembering Kate's misfortune is sufficient to prevent us from treating the closest worlds in which the same happens to Sophie as negligible exceptions among the closest parade-going worlds. Of course, (3) may be felicitously uttered to emphasize that Sophie's situation would be relevantly different (she may be much taller than Kate).

\subsection{Some qualifications in light of counterfactual scepticism}

The non-maximality solution is attractive, but there are several reasons why it might not completely cover Sobel- and Heim-sequences. The discussion of these reasons is thorny. My topic being counterfactual scepticism, I do not harbour the ambition of providing a full account of Sobel- and Heim-sequences. Still I shall venture some remarks concerning the dialectical role of counterfactual scepticism. Križ's solution is formulated within the standard account. It covers cases in which the closest $A \& B$ worlds are among the closest $A$-worlds. This leaves open the principled possibility that inspired David Lewis's (1973) original explanation of why Sobel-sequences can be true: they can be true provided there are no $A \& B$-worlds among the closest $A$-worlds.

If non-maximality were the only explanation of why Heim-sequences are infelicitous, Sobel-sequences should be felicitously reversible whenever Lewis's condition for their truth is satisfied. However, Križ himself notes that often reversals seem infelicitous even in this case:

'(17) Ginger was in Paris, so he couldn't have come to the party.

(18) But if both Nina and him had come, Adam would have been unhappy.

(19) \#Of course, if Nina had come, Adam would have been happy.

It is, however, possible to reverse counterfactual Sobel-sequences of the form if $A$, then $C$; if $A \& B$, then not $C$ only if they are interrupted by something like if $A$, then not $B$ :

(18) If Nina and Ginger had come, Adam would have been unhappy.

(17) Of course, Ginger was in Paris at the time and couldn't have come.

(19) So if Nina had come, Adam would have been happy.' (Križ 2015, p. 184, notation adapted) 
(17) signals that worlds where Ginger comes are not counted among the closest worlds where Nina comes, or so Križ assumes. But why then is (17)-(18)-(19) infelicitous as contrasted to (18)-(17)-(19)? Križ admits that he has no explanation.

The problem may even affect Križ's original non-maximality solution for the case in which there are $A \& B$-worlds among the closest $A$-worlds. Why should the $A \& B$ counterfactual explicitly raise to salience these $A \& B$-worlds as exceptions among the closest $A$-worlds given the alternative that they are less close than the closest $A$-worlds? The $A \& B$-counterfactual is silent about this alternative.

At this point, lessons from counterfactual scepticism apply. The considerations leading to counterfactual scepticism hugely expand the range of $A \& B$-worlds that are candidates for closest $A$-worlds. If we accept that there are closest antecedent worlds where the plate flies off sideways (2), we should also accept that, in cases like (17)-(18)-(19), worlds in which Ginger comes may figure among the closest worlds at which Nina comes. The possibility of Ginger coming does not even require weird physical ongoings like Ginger quantum-tunnelling to the party but only, say, using an airplane. In light of this possibility, we should read 'could' in (17) as contextually highly restricted. It is easy to make room for the possibility of Ginger coming. We should also accept:

(20) If Nina had come, Ginger might have (used an airplane and) come, too.

In this vein, the considerations that lead to counterfactual scepticism can be used to greatly expand the range of Sobel-sequences covered by the non-maximality solution. They may also explain why we normally are disposed to treat the worlds made salient by the $A \& B$-counterfactual as salient candidates for the closest $A$-worlds to be taken into account when assessing a subsequent $A$-counterfactual. Yet this expansion comes at a cost. To the extent it helps in explaining why reversals are infelicitous even in cases like (17)-(18)-(19), it makes it more difficult to explain felicitous reversals as noted in the literature.

Still there are resources for such an explanation. As for Križ's example (18)-(17)-(19), (17) inserted between (18) and (19) may be interpreted as a measure of restricting the worlds considered in (19) to worlds in which Ginger does not come. (17) might serve to introduce a similarity ordering in which the closest worlds in which Nina comes are closer than any worlds in which Ginger comes, or to change the issue such as to treat worlds in which Ginger comes, though closest, as irrelevant exceptions among the worlds in which Nina comes. For instance, the overarching issue might be whether to invite Nina in order to gratify Adam. One may start with some worries about Ginger coming, and then dismiss them as either too far-fetched or otherwise negligible.

These ways of dealing with (18)-(17)-(19) indicate strategies for dealing with purportedly felicitous reversals as presented in the literature (cf. De Jager 2009; Moss 2012; Klecha 2015; Lewis 2016, 2018; Nichols 2017). On the one hand, the conversation may shift back to an issue which permits treating worlds raised to salience by an $A \& B$-counterfactual as negligible. This will often take intermediate steps like (17). On the other hand, there may be contexts in which the closest $A \& B$-worlds are treated as less close than the closest $A$-worlds notwithstanding the lessons of counterfactual scepticism. Outright acceptance of the reversal will often take some special 
signalling (example in Moss 2012, p. 574). Some authors claim that a reversal is felicitous when we read $A \& B$-worlds as less close by default (e.g. Klecha 2015; Lewis 2018 , pp. 487-488). Yet for all the purported cases, even if we do not outrightly reject the reversal, the normal sequence sounds much better. This observation tends to be neglected. It sheds doubt on the default felicity of reversals.

In sum, the undeniable evidence to be explained is the widespread asymmetry in felicity between Sobel-sequences and their reversal. This asymmetry is well explained by the non-maximality solution, especially taking into account lessons from counterfactual scepticism.

\section{The non-maximality approach to counterfactual scepticism}

\subsection{Overview of the solution}

I shall now discuss in how far the non-maximality solution can be transferred to counterfactual scepticism. The prospects for such a transfer seem bright. The solution for Sobel- and Heim-sequences was troubled by potential differences in closeness between closest $A$ - and $A \& B$-worlds. This is not to be expected in the case of counterfactual scepticism, which only deals with antecedent worlds assumed to be maximally close. As we shall see, one of the main advantages of the non-maximality solution lies in respecting the intuition that the antecedent worlds adduced to support counterfactual scepticism are as close to actuality as normal antecedent worlds. As a consequence, even if non-maximality could not fully account for Sobel- and Heim-sequences, it might still be used to dissolve counterfactual scepticism.

Hegel-sequences are instrumental in mediating the transition from the solution for Sobel-sequences to the solution for counterfactual scepticism:

(n) If $A, C$.

(n+1) If $A$, might $B$ and then not $C$.

$(\mathrm{n}+1)$ If $A$, might $B$ and then not $C$.

(n) If $A, C$.

On the one hand, Hegel-sequences are to be treated largely like Sobel-sequences. Given the standard interpretation of a 'might'-counterfactual (some closest antecedent-world is a consequent world), one should expect Hegel-sequences to correspond to precisely those Sobel-sequences to which the non-maximality solution applies: for each such true Sobel-sequence, there should be a parallel true Hegel-sequence. Their reversal should be infelicitous.

On the other hand, we have seen that the key examples of counterfactual scepticism are formulated by 'might'-counterfactuals. The sequence (1)-(2) seems all right:

(1) If the plate had been dropped, it would have shattered;

(2) (if the plate had been dropped,) it might have flown off sideways and then it would not have shattered.

Yet the reverse sequence is infelicitous:

(2) If the plate had been dropped, it might have flown off sideways and then it would not have shattered; 
(1) \#(if the plate had been dropped,) it would have shattered.

The parallel to Sobel-sequences supports the following explanation: when the forward-directed sequence (1)-(2) is felicitous, the final meaning of (1) is given by a non-maximal reading. Semantically speaking, (1) is not true as some closest antecedent worlds are worlds where the plate flies off sideways. But taking into account pragmatics, (1) is used to convey something true: normally, the conversational issue is whether practically all closest dropping-worlds are shattering-worlds. It does not matter whether (1) is semantically true, i.e. all closest dropping-worlds are shatteringworlds, or only close enough to being s-true, i.e. all closest dropping-worlds save some exceptions are shattering-worlds. If (1) excels compared to alternative ways of addressing the issue in terms of manner, it should be chosen regardless of whether it is semantically true or not. Hence we read an utterance of (1) as conveying that, for the purposes of conversation, the actual situation is equivalent to a situation where (1) is s-true: there is at most a negligible range of exceptions where the plate does not shatter. In contrast, (2) is s-true as the plate flies off in some closest worlds where it is dropped.

As for the reversal, once the exceptions, i.e. closest dropping-worlds where the plate flies off sideways, are mentioned by uttering (2), they cannot be neglected. Once (2) is uttered, the difference between all closest antecedent worlds and all closest antecedent worlds save some amazing exceptions being consequent worlds matters for the purposes of conversation. In the context inherited from an uttrance of (2), (1) cannot be used to say that practically all closest dropping-worlds are shattering-worlds. An issue usually is not determined retrospectively but prospectively. A later utterance of (2) cannot change the issue addressed by an earlier utterance of (1), but once (2) is uttered, the issue to be addressed by a subsequent utterance of (1) does not allow for exceptions (of the sort made salient).

The crucial result: an explanation in terms of non-maximality avoids scepticism at the use level. Counterfactuals like (1) are normally used to convey something true. Scepticism is not refuted at the semantic level. Semantically, most everyday counterfactuals are not true (and not false either). But I do not see why this result should be problematic. We only have to avoid that most everyday utterances of counterfactuals (including pragmatics) fail to be true. ${ }^{10}$

In Križ's analysis, an utterance read non-maximally must address an issue. How does this requirement square with the claim that we deem (1) true 'out of the blue'? Just as for the examples of descriptions (6) and (9), we are willing to supplement the minimal context given. In the case of (1), we supplement an issue that is streamlined by certain normalcy assumptions. To bring out these assumptions, I draw a comparison to our reasoning about actual situations: assume one is told that the plate was dropped. One is disposed to conclude that it shattered as long as one has no further information. One normally disregards epistemic alternatives like the plate flying off sideways. I suggest that the same routines of reasoning that make one disregard such alternatives are also in play in our 'out of the blue' reaction to counterfactuals like (1). ${ }^{11}$

\footnotetext{
10 The lesson about utterances surely generalizes to thinking in terms of counterfactuals, which in this respect resembles their use in a conversation.

11 Drawing on cognitive science, it is suggested that we assess everyday counterfactuals by a quasiNewtonian '...mental physics engine with an approximate understanding of bodies and the forces acting
} 
Having summarized the solution, I shall elaborate some advantages of the account compared to alternative proposals.

\subsection{The versatility of the pragmatic solution}

One main advantage of the pragmatic solution compared to its rivals is that it perfectly compatible with the line of reasoning that drives counterfactual scepticism. Take again the plate counterfactual (1). The semantic truth of (1) depends on all closest antecedent worlds, on the few worlds where the plate flies off sideways just as on the overwhelmingly many worlds where the plate shatters. The reasoning can be further supported by conceiving of antecedent worlds at the level of microphysical detail. None of these individual worlds seems less relevant or less close than the other, including those in which the plate flies off sideways.

To explain why an utterance of (1) is normally true, proponents of semantic approaches like Lewis (2016, 2018) or Gillies (2007) have to dismiss the flying-off worlds either as less relevant (Lewis) or as less similar (Gillies) to the actual world than some shattering worlds. In the non-maximality approach, a different interpretation is readily available: flying-off worlds do not only count towards the semantic truth or falsity of (1). They may also be relevant to the eventual truth of an utterance of (1).

For comparison, consider the following version of the example of the smiling professors: it is no less relevant whether Smith smiled than whether any other professor smiled. The question is simply whether practically all professors smiled. Once Smith not smiling is raised to salience,

(9) The professors smiled

is infelicitous. This is not because Smith smiling now becomes relevant, but because the threshold for the number of smiling professors has changed. We cannot any longer treat a situation in which just one professor does not smile as equivalent to a situation in which all professors smiled.

To be sure, the situation described is only one of those in which (9) can be truly uttered. The situation may also be one in which it is indeed irrelevant whether Smith smiles, even it he is maximally salient, perhaps because it is common knowledge that he never smiles. The non-maximality approach can also handle such a situation: the issue becomes whether every professor save perhaps Smith smiled.

The lesson can be transferred to counterfactuals. Take:

(3) If Sophie had gone to the parade, she would have seen Pedro dance;

(4) if Sophie had gone to the parade, she might have been stuck behind someone tall and then wouldn't have seen Pedro dance.

In order to explain our acceptance of (3), the semantic approaches mentioned have to treat the worlds where Sophie gets stuck either as less relevant or as less similar to the actual world than some worlds where she sees Pedro. Then a context shift can be used to explain our acceptance of (4). Yet it seems highly plausible that there are contexts in

Footnote 11 continued

on them.' (McCoy et al. 2019, p. 237) Presumably such a mental engine would tell us simply that the plate shatters. Given our preparedness to listen to quantum physics, our use of the mental engine should be interpreted as merely heuristical. It may also inform our expectations about the normal issue to be addressed. 
which the closest getting-stuck worlds are no less relevant or similar to actuality than the closest parade-going worlds where Sophie does not get stuck. There are just fewer of them. Still we may be disposed to accept (3). This is confirmed by the parallel to the chicken counterfactual (21) (if we were to eat the chicken, we would get sick). ${ }^{12}$ As I have argued, the closest worlds in which we eat the chicken and stay healthy are no less similar or relevant than the closest worlds where we get sick. The non-maximality approach can easily handle such contexts. If the issue is whether Sophie sees Pedro in sufficiently many closest parade-going worlds, (3) may be truly uttered although worlds where Sophie gets stuck are maximally similar and relevant.

Again there are other possible contexts in which we specifically dismiss or just ignore worlds in which Sophie gets stuck. The non-maximality approach is flexible enough to deal with all the different contexts in which (3)-(4) is acceptable, including those in which worlds where Sophie gets stuck are dismissed as irrelevant or ignored. Often some sort of normalcy heuristics will be in play (cf. Kahneman and Tversky 1973). The use of such heuristics can also be construed in different ways. Sometimes they may lead to just ignoring certain worlds, sometimes they may be used to weigh the proportion of normal and atypical worlds.

Our acceptance of (1) can be plausibly construed along the same lines: the default issue to be addressed in a conversation is streamlined by heuristics. The latter guide us in ignoring worlds where the plate flies off or in determining a threshold of closest dropping-worlds that have to be shattering-worlds. The last option in particular does not have to come with demoting flying-off worlds from being maximally similar or relevant. In each case, the alternative that only the normal worlds are shattering-worlds is treated as equivalent to the alternative that all closest worlds are for the purposes of conversation.

In sum, the non-maximality approach has several advantages compared to the semantic alternatives considered: the exceptions that give rise to counterfactual scepticism do not have to be treated as less similar than the most similar antecedent worlds or as somehow less relevant. There are many ways of handling these exceptions like counting, weighing, dismissing, and simply disregarding them.

\subsection{Retraction}

I shall close with considering evidence from retraction. There is a variety of reactions to the considerations fueling counterfactual scepticism:

\section{DIALOGUE 4}

$\mathrm{Al}$ : (1) If the plate had been dropped, it would have shattered.

Bo: That's not true. Considering quantum phenomena,

(2) if the plate had been dropped, it might have flown off sideways and then it would not have shattered.

$\mathrm{Al}$ : (21) But I wanted to consider what normally happens.

Alternatively, Al might continue as in DIALOGUE 3:

12 One way of testing this prediction would be a context in which we first explicitly enumerate all relevant and maximally similar ways for Sophie to go to the parade, among them those in which she gets stuck. If there are sufficiently few of them, we may still be disposed to utter (3)-(4). 
$\mathrm{Al}:$... I admit that,

(2) if the plate had been dropped, it might have flown off sideways and then it would not have shattered.

Hence (what I said was not quite right):

(12) it is not the case that, if the plate had been dropped, it WOULD/would definitely have shattered

According to Karen Lewis, disagreement as exemplified by (21) in DIALOGUE 4 'is not disagreement in the sense of disagreeing about the truth of a specific proposition, but rather disagreement about what the relevant context is or should (or can) be' (Lewis 2016, p. 302). The non-maximality approach leads to the same result, the disagreement concerning a matter of pragmatics. Al and Bo disagree whether the contextual issue licenses a non-maximal use of (1). In DIALOGUE 3, Al gives in and accepts the contextual issue as suggested by Bo. ${ }^{13}$ In DIALOGUE 4 (21), he embarks on metalinguistic negotiation. ${ }^{14}$ Normally raising a neglected possibility to salience shifts the issue. The possibility cannot be neglected any longer. It takes explicit negotiation to counteract this change. Such negotiation is initiated by Al when he insists that he was interested only in the normal outcomes.

\section{Conclusion}

I have discussed the prospects of transferring the non-maximality solution for Sobeland Heim-sequences to counterfactual scepticism. The combination of semantic homogeneity and pragmatic non-maximality is a relevant alternative to the approaches on offer. The non-maximality approach is highly flexible. We can even accept the core argument for counterfactual scepticism: among the many and varied closest antecedent worlds (e.g. where the plate is dropped in (1)), there will usually be some in which the consequent is false (the plate does not shatter). These worlds do not have to be treated as less similar or less relevant than other antecedent worlds for the utterance of a normal counterfactual like (1) to be true. A counterfactual may be truly uttered as far as the contextual issue addressed only requires that practically all closest antecedent worlds are consequent worlds.

Acknowledgements Open access funding provided by Università degli Studi di Milano within the CRUICARE Agreement. My thanks go to Manuel Križ, the participants of the Fourth Taiwan Philosophical Logic Colloquium, and two anonymous reviewers for Synthese.

Open Access This article is licensed under a Creative Commons Attribution 4.0 International License, which permits use, sharing, adaptation, distribution and reproduction in any medium or format, as long as you give appropriate credit to the original author(s) and the source, provide a link to the Creative Commons licence, and indicate if changes were made. The images or other third party material in this article are included

\footnotetext{
13 Why can Al even accept that what he said 'was not quite right'? I followed Lauer (2012) in suggesting that a speaker is committed to the semantic truth of her utterance, but she can expect to 'get away' with a non-maximal reading if everyone agrees. This expectation is disappointed in DIALOGUE 3 and 4.

14 Given my assumption that the speaker remains committed to the semantic truth of her utterance, I have to assume an asymmetry between someone who relies on the non-maximal reading and someone who insists on the semantic truth-condition. A speaker cannot insist on the permission to use a sentence non-maximally; she can only suggest to her opponent to condone such a use. This is how I read Al's (21).
} 
in the article's Creative Commons licence, unless indicated otherwise in a credit line to the material. If material is not included in the article's Creative Commons licence and your intended use is not permitted by statutory regulation or exceeds the permitted use, you will need to obtain permission directly from the copyright holder. To view a copy of this licence, visit http://creativecommons.org/licenses/by/4.0/.

\section{References}

Asher, N., \& McCready, E. (2007). Were, would, might and a compositional account of counterfactuals. Journal of Semantics, 24, 93-129.

Bittner, M. (2001). Topical referents for individuals and possibilities. SALT, 11, 36-55.

Chierchia, G., \& McConnell-Ginet, S. (1999). Meaning and grammar. An introduction to semantics. Cambridge, MA: MIT Press.

De Jager, S. T. (2009). 'Now that you mention it, I wonder...': Awareness, Attention, Assumption. Ph.D. dissertation, Amsterdam. http://dare.uva.nl/record/323944.

Evans, J., \& Over, D. (2004). If . Oxford: Oxford University Press.

Gauker, C. (2005). Conditionals in context. Cambridge, MA: MIT Press.

Gillies, A. (2007). Counterfactual scorekeeping. Linguistics and Philosophy, 30, 329-360.

Hájek, A. (ms). Most counterfactuals are false.

Ippolito, M. (2020). Varieties of Sobel sequences. Linguistics and Philosophy. https://doi.org/10.1007/s10 988-019-09281-8.

Kahneman, D., \& Tversky, A. (1973). On the psychology of prediction. Psychological Review, 80, $237-251$.

Klecha, P. (2015). Two kinds of Sobel-sequences. Precision in conditionals. Proceedings of WCCFL, 32, $131-140$.

Klecha, P. (2018). On unidirectionality in precisification. Linguistics and Philosophy, 41, 87-124.

Krifka, M. (2002). Be brief and vague! and how bidirectional optimality theory allows for verbosity and precision. In D. Restle \& D. Zaeferer (Eds.), Sounds and systems: Studies in structure and change: A festschrift for Theo Vennemann (pp. 439-458). Berlin: Mouton de Gruyter.

Križ, M. (2015). Aspects of homogeneity in the semantics of natural language. Unpublished Ph.D. dissertation.

Križ, M. (2016). Homogeneity, non-maximality, and all. Journal of Semantics, 33, 493-539.

Križ, M., \& Chemla, E. (2015). Two methods to find truth-value gaps and their application to the projection problem of homogeneity. Natural Language Semantics, 23, 205-248.

Lauer, S. (2012). On the pragmatics of pragmatic slack. Sinn und Bedeutung, 16, 389-401.

Lewis, D. (1973). Counterfactuals. Oxford: Blackwell.

Lewis, D. (1979). Scorekeeping in a language game. Journal of Philosophical Logic, 8, 339-359.

Lewis, D. (1986). Counterfactual dependence and time's arrow, postscripts to 'counterfactual dependence and times's arrow'. In D. Lewis (Ed.), Philosophical Papers (Vol. II, pp. 32-66). Oxford: Oxford University Press.

Lewis, K. (2016). Elusive counterfactuals. Noûs, 50, 286-313.

Lewis, K. (2018). Counterfactual discourse in context. Nô̂s, 52, 481-507.

Malamud, S. (2012). The meaning of plural definites: A decision-theoretic approach. Semantics and Pragmatics, 5, 1-58.

McCoy, J., et al. (2019). Modal prospection. In A. J. Goldman \& B. P. McLaughlin (Eds.), Metaphysics and cognitive science (pp. 235-267). Oxford: Oxford University Press.

Moss, S. (2012). On the pragmatics of counterfactuals. Noûs, 46, 561-586.

Moss, S. (2013). Subjunctive credences and semantic humility. Philosophy and Phenomenological Research, 87, 251-278.

Nichols, C. (2017). Strict conditional accounts of counterfactuals. Linguistics and Philosophy, 40, 621-645.

Schlenker, P. (2004). Conditionals as definite descriptions. Research on Language and Computation, 2, 417-462.

Stalnaker, R. (1968). A theory of conditionals, studies in logical theory. American Philosophical Quarterly Monograph, 2, 98-112.

Von Fintel, K. (1997). Bare plurals, bare conditionals, and Only. Journal of Semantics, 14, 1-56.

Von Fintel, d. (2001). Counterfactuals in a dynamic context. In M. Kenstowicz (Ed.), Ken Hale: A life in language (pp. 123-152). Cambridge, MA: MIT Press. 
Williams, J. R. G. (2008). Chances, counterfactuals, and similarity. Philosophy and Phenomenological Research, 78, 385-420.

Publisher's Note Springer Nature remains neutral with regard to jurisdictional claims in published maps and institutional affiliations. 